\title{
TIDAL EARTH CRUST DEFORMATION MEASUREMENTS
}

\author{
Denis Dontsov ${ }^{1}$, Wolfgang Pöschel ${ }^{1}$, Walter Schott ${ }^{1}$, \\ Nina Kukowski ${ }^{2}$, Thomas Jahr ${ }^{2}$, Peter Schindler ${ }^{2}$ \\ ${ }^{1}$ SIOS Meßtechnik GmbH, Ilmenau, Germany \\ ${ }^{2}$ Institute of Geosciences, Friedrich Schiller University Jena, Germany
}

\begin{abstract}
This paper presents an application of the fiber coupled homodyne interferometers for the tide caused earth crust deformation measurements. Deformation of the earth crust mainly results from the tidal forces of sun and moon acting on the Earth, but also comes from seismic wave propagation or regional and local sources. The devices used for monitoring of such processes called strainmeters. The Geodynamic Observatory Moxa in Thuringia/Germany records and compares over the years the values gained by different stainmeters. The first laser interferometer was installed in the observatory in 2002. The new laser interferometer based setup, presented in this paper, allows direct monitoring of north-south and east-west components of the earth deformation in the range of 1-2 $\mu \mathrm{m}$ at measuring distances of $26 \mathrm{~m}$.
\end{abstract}

Index Terms - Strainmeter, laser interferometer, He-Ne-laser, length measurement

\section{INTRODUCTION}

Deformation of the earth crust mainly results from the tidal forces of sun and moon acting on the Earth, but also comes from seismic wave propagation or regional and local sources. Strainmeters allow the observation of crustal deformation with a resolution better than $10^{-9} \mathrm{~m}$. At the Geodynamic Observatory Moxa in Thuringia/Germany an assembly of strainmeters of different types record the deformation. The analysis of the strainmeter data shows the comparability of the data from the different instruments as well as the good data quality connected to the very low noise level at the Geodynamic Observatory Moxa [1]. The strainmeter systems described in this paper are long range laser interferometers of Michelson type. These interferometers with corner cube reflectors are precision length measurement instruments and coupled by optical fibers [2]. They are specially designed for long range operation under difficult environmental conditions. The interferometers are installed in the Geodynamic Observatory in a gallery dug horizontally intro the adjacent slope. The measuring ranges are 26 and 38 meters. The resolution of the systems is about $1 \mathrm{~nm}$. All interferometers are designed for long-term measurements over several weeks.

To minimize the influence of temperature and air pressure changes on the interference fringes due to the dependence of the refractivity index of air on these values ([9], [10], [11]), the horizontal borehole for the diagonal $38 \mathrm{~m}$ strain is sealed at both ends with a special glass and the $26 \mathrm{~m}$ strains use the hermetic metal tubes for the laser beam protection.

All data are sampled every $10 \mathrm{~s}$. In addition, inside the gallery several sensor measure variations of temperature, air pressure or humidity. At the laser strainmeter, another air pressure sensor is installed and five temperature sensors are placed at different points along the laser beam. Outside the observatory building, a meteorologic station records environmental parameters. 


\section{HOMODYNE INTERFEROMETER}

Displacement measuring homodyne interferometers are interferometers which use an one frequency light source and compare the measuring displacement with a light wavelength. The devices allow ultraprecise measurements with nanometer-scale resolutions. A metrological analysis of the measuring method involved shows the opportunities they afford and the metrological limits of laser-interferometric systems. For that purpose, consider a Michelson interferometer, the basic type of interferometer for displacement measurements, and assume that the laser light source employed emits plane waves that are split into a pair of coherent, partial waves and interfere through superposition. The intensity distribution in the image plane will then be give by Eq. 1:

$$
I=I_{1}+I_{2}+2 \sqrt{I_{1} I_{2}} \cos \left(\frac{2 \mathrm{pi}}{\lambda_{0}} \cdot n \cdot i \cdot s\right),
$$

where $I$ is the intensity, $I_{1}$ is the intensity of partial wave $1, I_{2}$ is the intensity of partial wave 2 , $\gamma$ is the phase angle of the measurement, $\lambda_{0}$ is the source vacuum wavelength, $n$ is the refractive index of the transmitting medium, $i$ is the interferometer factor (the optical interpolation factor, and $\mathrm{s}$ is the displacement to be measured.

From Eq. 1, it follows that

$$
s=\frac{d \cdot \lambda_{0}}{i \cdot n},
$$

where $\delta$ is the order of interference, from which the smallest, resolved displacementquantization unit, $\mathrm{s}_{\mathrm{q}}$, may be derived as

$$
s_{q}=\frac{\lambda_{0}}{e \cdot i \cdot n},
$$

where e is the electronic interpolation factor.

Eq. 3 shows that Michelson interferometers are capable of attaining extraordinarily fine resolutions. Resolutions extending down to $0.1 \mathrm{~nm}$ are possible, even over large displacement ranges, using precision interferometers and the current state of the art in electronic signalprocessing equipment.

The improved interpolation method of homodyne interferometers achieve resolutions bellow $0.1 \mathrm{~nm}$. For a displacement range of $1 \mathrm{~m}$, relative resolutions of $\leq 10^{-10}$ are attainable. The total number of length increments (pulse count) is determined by the order of interference, $\delta$, and the electronic interpolation factor, e, which defines the number of pulses, into which a signal period is subdivided. Various factors that influence the limits of the laserinterferometric method must be taken into account when determining metrological precisions or measurement errors. Eq. 2 defines the effects of such factors on measured displacements. The refractive index, $\mathrm{n}$, of air is a function of air temperature, barometric pressure, humidity, and other factors. Measurements of those factors allow making computational corrections for them using the Edlén formula. 
The stability of the wavelength, $\lambda_{0}$, of the laser light source employed is another influencing factor. The He-Ne lasers employed on homodyne interferometers are noted for their long-term frequency stabilities and particularly well suited to use in high-precision length measurements. Determinations of their absolute mode wavelengths and frequency stabilities involve interfacing them to an iodine-vapor-stabilized He-Ne laser.

The frequency stabilities of iodine-vapor-stabilized He-Ne lasers approach $10^{-11}$. The frequency-stabilized He-Ne lasers employed on homodyne interferometers attain long-term frequency stabilities of $\leq 2 \times 10^{-8}$.

These interferometer systems for precision distance measurements have the following major features:

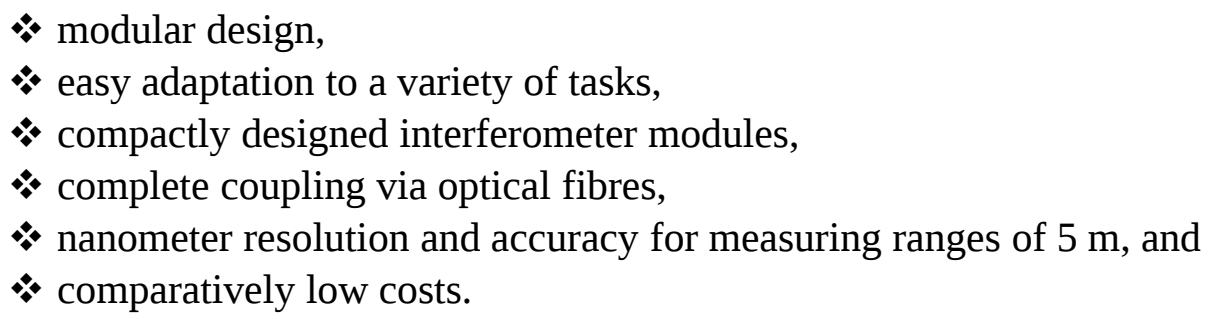

Various factors that limit the precision of laser-interferometric length measurements must be taken into account in determining the precision and accuracy of the method. Eq. 2 may be used to compute the effects of such factors on the results of length measurements.

The refractive index, $\mathrm{n}$, of air is a function of the ambient temperature, barometric pressure, and absolute humidity. The extent to which these factors affect the results of length measurements may be seen from Table 1 . Corrections may be made if these parameters are measured.

Table 1: The effects of ambient temperature, barometric pressure, and humidity on the refractive index of air, $\mathrm{n}$.

\begin{tabular}{|l|l|}
\hline$\frac{\Delta n}{n}=-0.929 \cdot 10^{-6} \mathrm{~K}^{-1} \cdot \Delta \delta$, & where $\Delta \delta$ is the change in ambient temperature, \\
\hline$\frac{\Delta n}{n}=+2.682 \cdot 10^{-9} \mathrm{~Pa}^{-1} \cdot \Delta p$, & where $\Delta \mathrm{p}$ is the change in barometric pressure, \\
\hline$\frac{\Delta n}{n}=-3.84 \cdot 10^{-10} \mathrm{~Pa}^{-1} \cdot \Delta \mathrm{p}_{F}$, & $\begin{array}{l}\text { where } \Delta \mathrm{p}_{\mathrm{F}} \text { is the change in water-vapor partial } \\
\text { pressure. }\end{array}$ \\
\hline
\end{tabular}

The stability of the wavelength, $\lambda_{0}$, of the laser light source employed is a second major factor affecting metrological precision. Table 2 lists the relative wavelength stabilities of various laser light sources. In order to determine the absolute modal wavelength of a frequencystabilized He-Ne-laser, it must be slaved to an iodine-vapor-stabilized He-Ne-laser that is linked to the cesium atomic clock of a national standards institute. The number of increments (counter pulses) is the product of the order of interference, $\delta$, involved and the electronic interpolation factor, e. The electronic interpolation factor, e, thus specifies the number of pulses into which a signal period is subdivided. The resultant interpolation errors should also be taken into account. 
Table 2: The relative wavelength stabilities of various types of laser light sources.

\begin{tabular}{|l|l|}
\hline Laser light source & $\pm \Delta \lambda_{0} / \lambda_{0}$ \\
\hline Unstabilized single-frequency He-Ne-lasers & $\approx 10^{-6}$ \\
\hline Unstabilized dual-frequency He-Ne-lasers & $\begin{array}{l}\approx 3 \times 10^{-7} \text { (for max. path-length dif- } \\
\text { ferences }<\text { their resonator length) }\end{array}$ \\
\hline $\begin{array}{l}\text { Stabilized He-Ne-lasers (for the case of equal mode } \\
\text { intensities) }\end{array}$ & $<10^{-8}$ \\
\hline Iodine-vapor-stabilized He-Ne-lasers & $\approx 10^{-12}$ \\
\hline Diode lasers & $\approx 10^{-5}$ \\
& $10^{-6}$ short-term stability \\
\hline
\end{tabular}

\section{FIBER-COUPLED HOMODYNE INTERRFEROMETERS}

The homodyne interferometers presented here are Michelson interferometers. Fig. 1 shows such interferometer, configured in the form interferometer with cube corner reflector.

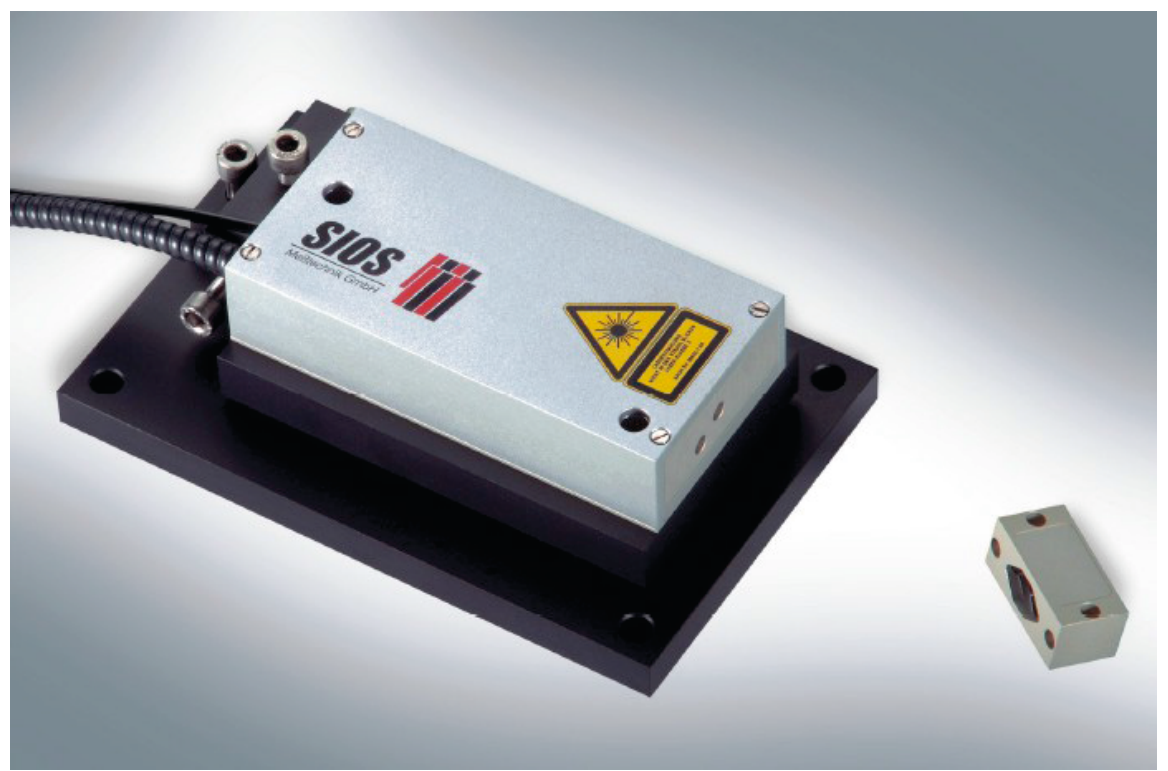

Fig. 1 Fully fiber-coupled homodyne interferometer sensor

Both the laser light source and power-supply/signal-processing unit are separated from the measurement head. Light from the frequency-stabilized He-Ne laser is transmitted to the measurement head on a single-mode fiberoptic lightguide, which allows keeping heat sources well away from the location where measurements are conducted. The advantage of the metrological method presented here is based on transmitting just a single beam that is retroreflected by the moving reflector per measurement axis, which allows configuring the metrological setup such that there will be a well-defined point of contact with the object being measured and that the laser beam will remain accurately aligned on the measurement axis, which, in turn, means that the configuration of an Abbé comparator will be maintained. Abbé errors, a typical error source, will thus be minimized or totally eliminated. Such interferometers have nanometer precisions and excellent linearities over displacements in meter range. The presented interferometer type is used in the application for the earth crust deformation measurement, because of the low heat generation and simple design. 


\section{INTERFEROMETER APPLICATION FOR TIDAL EARS CRUST DEFORMATION MEASUREMENT}

The Geodynamic Observatory Moxa consists of a three-part building located at the foot of a hill, and a gallery dug horizontally into the adjacent slope. The gallery is separated from the building by several doors to keep environmental conditions, especially temperature, as stable as possible. Its instrumentation consists of different types of measurement systems, including besides strainmeters also tiltmeters, seismometers, a superconducting gravimeter as well as a spring gravimeter (for details see [3]). Additionally, outside the observatory and in the surrounding area a large number of sensors record environmental parameters like air pressure, temperature, wind, or soil moisture. All strainmeters are installed inside the gallery. The $26 \mathrm{~m}$ long quartz tube strainmeters and the $38 \mathrm{~m}$ long laser strainmeter are connected to the ground by steel pillars whereas the borehole instrument is installed at about $10 \mathrm{~m}$ depth and the borehole filled up with concrete. The quartz tube strainmeters are oriented in east-west and north-south direction, respectively, along the two arms of the gallery. Distance changes along the two quartz tube strainmeters are measured by inductive sensors. The laser diagonal instrument connects the far ends of the quartz tube strainmeters through a horizontal borehole, and the borehole strainmeter is installed at the gallery elbow. The new laser based strainmeters have been installed parallel to quartz strainmeters, so they build now the completely triangular system for crust deformation monitoring. The Fig. 2 shows an assembly of the laser-interferometric strainmeters in the observatory.

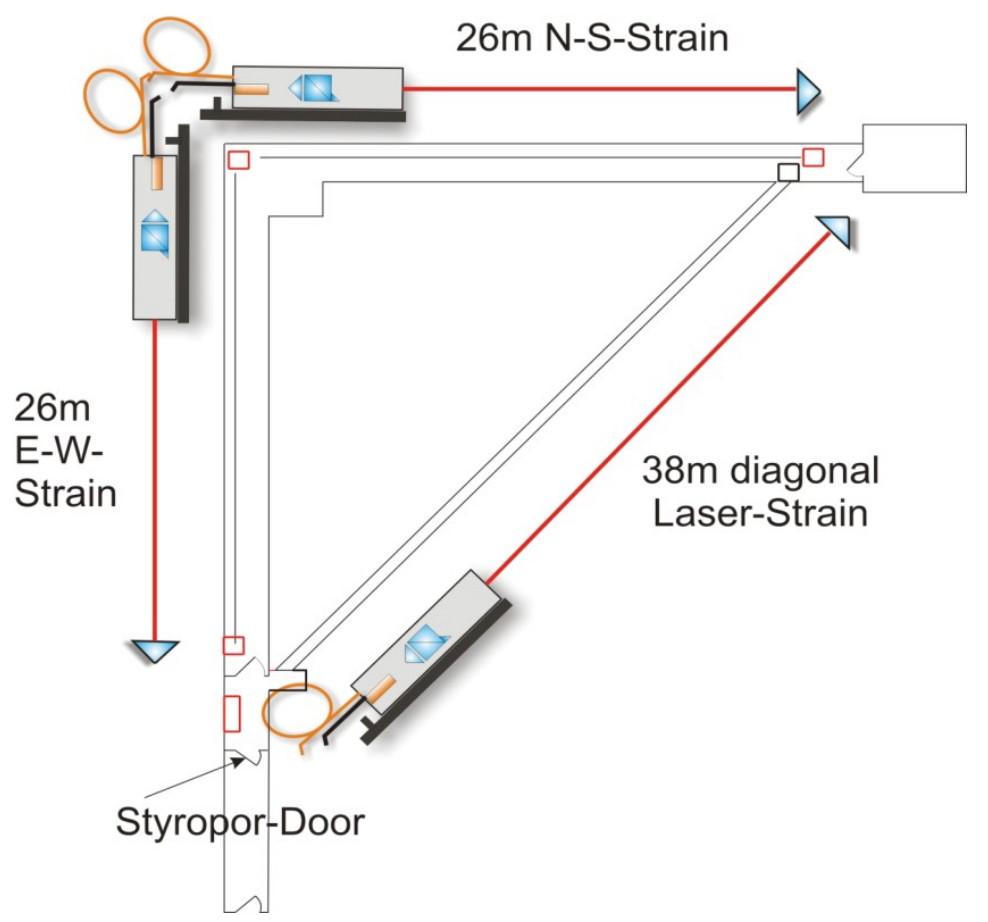

Fig. 2 Assembly of laser strainmeters at the Geodynamic Observatory Moxa

The interferometers used as laser strainmeters are modified fiber coupled homodyne interferometers with cube corner reflector (Fig. 1). The high humidity at the measuring location of about $100 \%$ and the long stand-off distance of the reflector cause main problems for the interferometer design. To minimize the influence of temperature and air pressure changes on the interference fringes due to the dependence of the refractive index of air on 
these values, the horizontal bore $38 \mathrm{~m}$ hole is sealed at both ends with a special glass and the $26 \mathrm{~m}$ strains use the hermetic metal tubes for the laser beam protection. Fig. 3 presents the measuring principle of the laser-interferometric strainmeters.

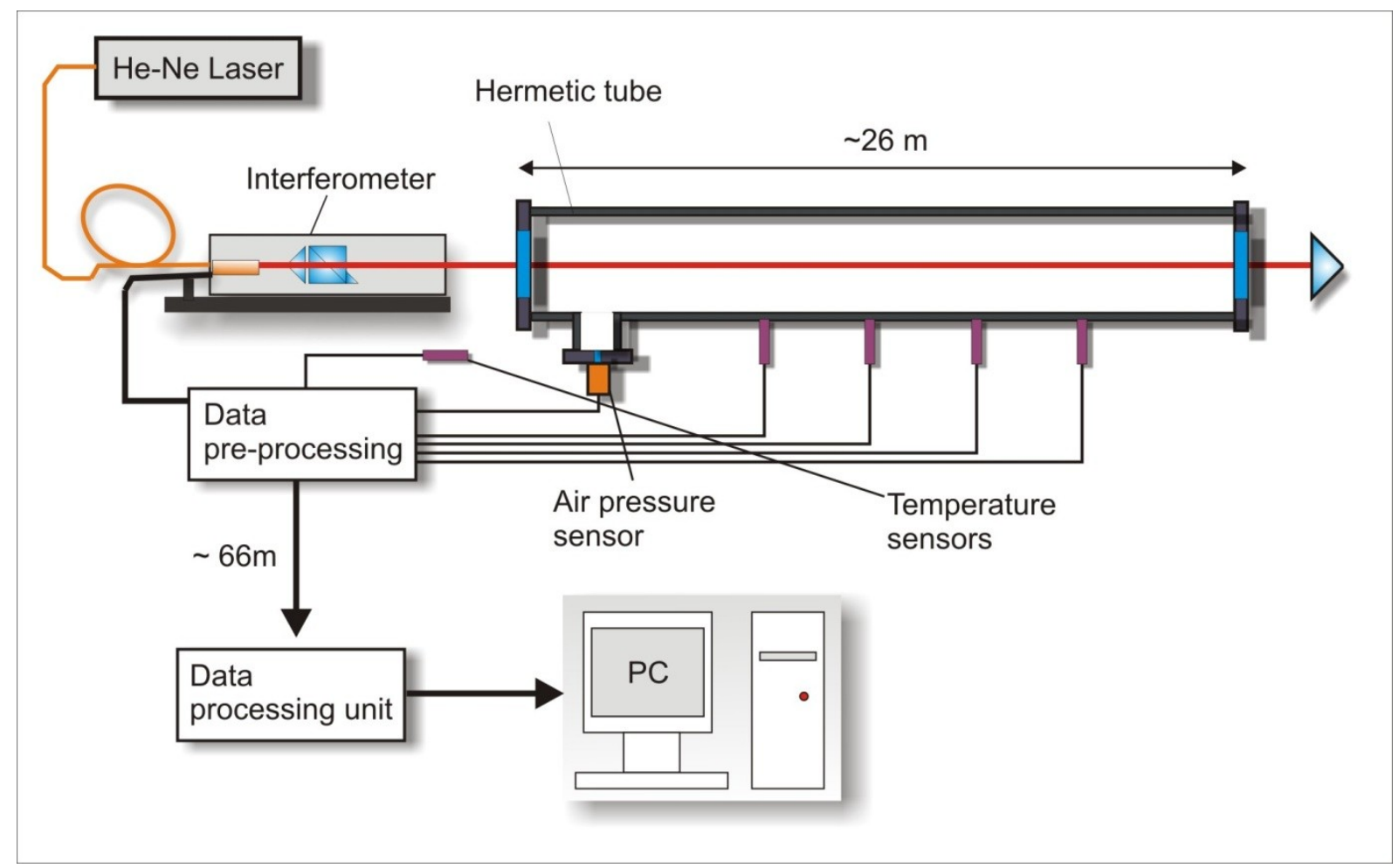

Fig. 3 Measuring principle of the laser-interferometric strainmeter

The light source for the interferometer is a modified fiber coupled SL-03 He-Ne laser of SIOS, which is placed outside the device and outside the gallery behind the styropor door. The light comes to the interferomer via single mode PM-fiber. The measuring beam of the interferomer goes through the tube with two glass windows. The tube is intended to be hermetic sealed. The air pressure sensor is installed on the tube and four temperature sensors are placed at different points along the laser beam. In addition, the one temperature sensors measures the temperature inside the gallery. This interferometer setup is used for both N-S and E-W strains. Also diagonal laser-interferometric strainmeter has similar setup. Fig. 4 shows the interferometers of the strains in gallery.
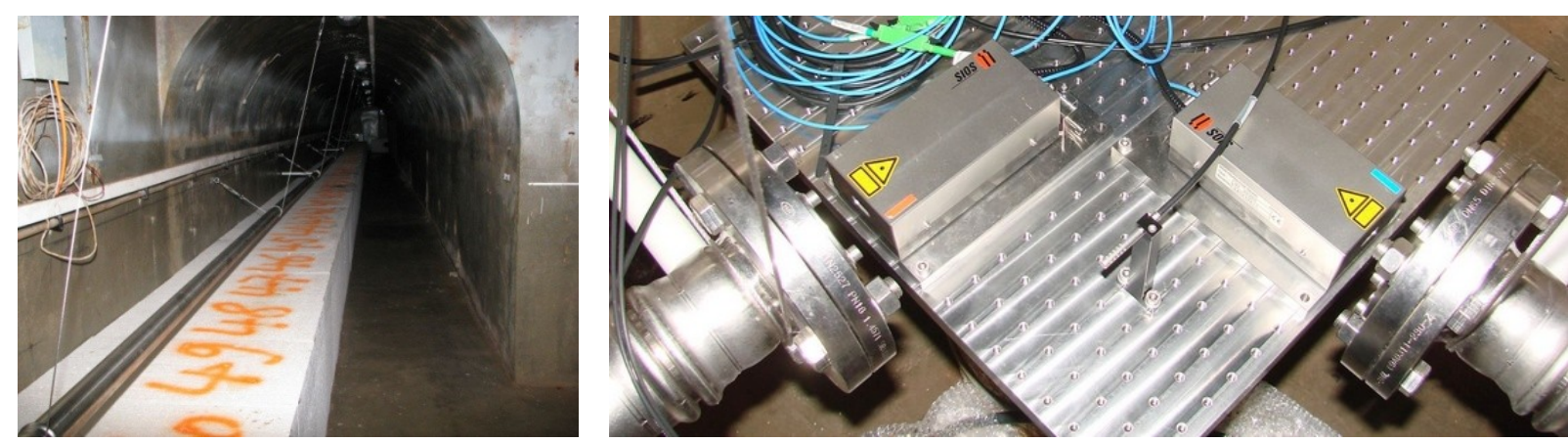

Fig. 4 Thermally isolated north-south strain (left) and interferometer base for $N$-S and E-W strains (right)

The usual correlations of the interferometer measuring results in air to the temperature and to the air pressure are very high, as it was described in previous sections. The natural temperature stability in the gallery is only some tens of Kelvin over the year. But the air 
pressure changes are directly influences by the external natural effects. Therefore the variations of the air pressure along the measuring beam plays the main role for the stability of the measuring results.

The Fig. 5 presents the stability of temperature of N-S strain over 8 hours.

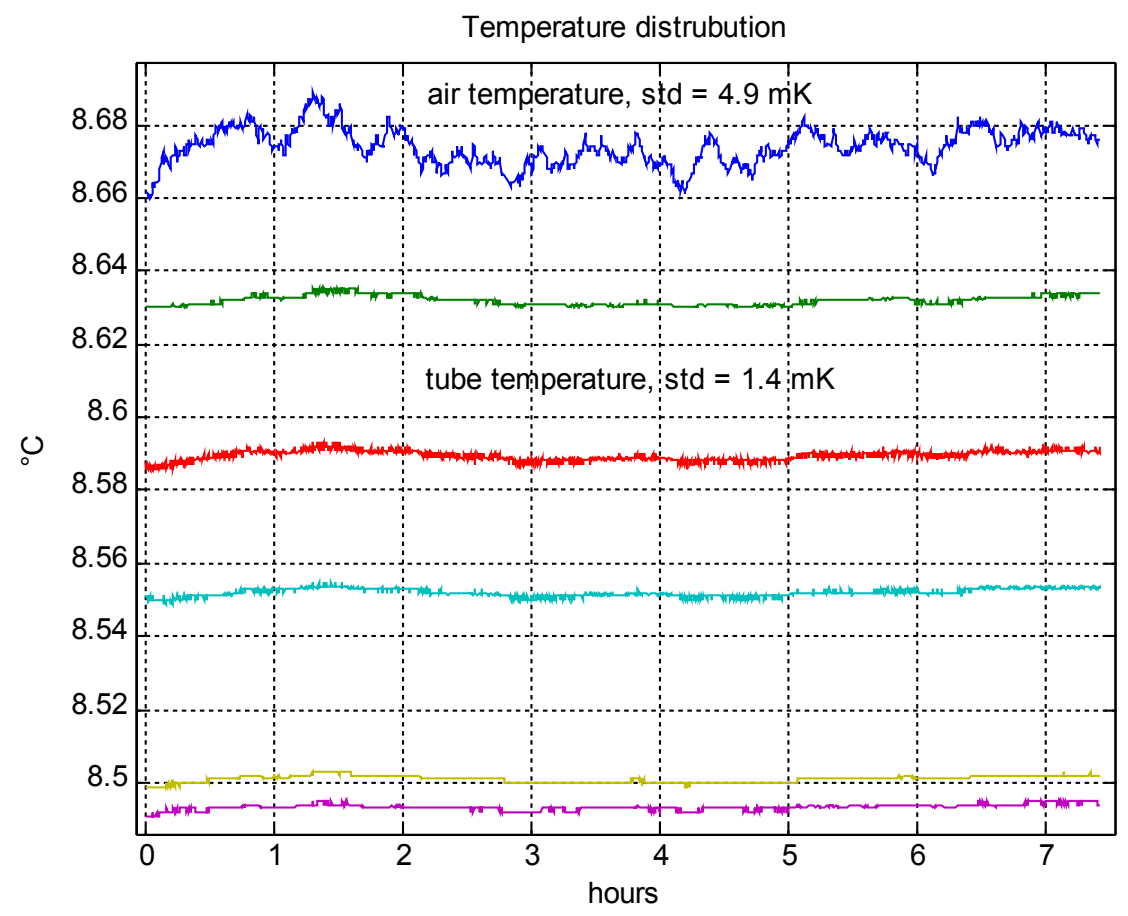

Fig. 5 Stability of the temperature of $N$-S strain

The natural standard deviation of the air temperature in the gallery over 8 hours is about 5 $\mathrm{mK}$. This temperature influences only short part of the interferometer measuring beam before and after the hermetic tube. The hermetic tube is additionally isolated from the environment by styropor material. Four other temperature sensors are connected to the tube and measure the temperature variations along the measuring beam. These sensors are used for monitoring purposes only. As is presented in Fig. 5 the standard deviation of the temperature along the beam is in the range of $1.5 \mathrm{mK}$.

The variations of the air pressure for N-S and E-W strains is presented in Fig. 6. It is measured inside the hermetic tube along the measuring beam of interferometers. For the air pressure measurements the high-precision resonance pressure sensor RPT201 is used. The sensor is temperature compensated and provides the air pressure dependent frequency output. In order to minimize the power consumption of the electronics these sensor digital outputs are converted in the data pre-processing box into the analogue harmonic signals and transferred over more than 66 meters to the main data processing station. As is presented in the Fig. 6, the high stability of the air pressure in the tube was achieved. Over the 12 day both sensors show the standard deviations of variations of the air pressure in the range of $1.6 \mathrm{~Pa}$. Therefore the influence of these parameters to the measuring result of the interferometer can be neglected. 


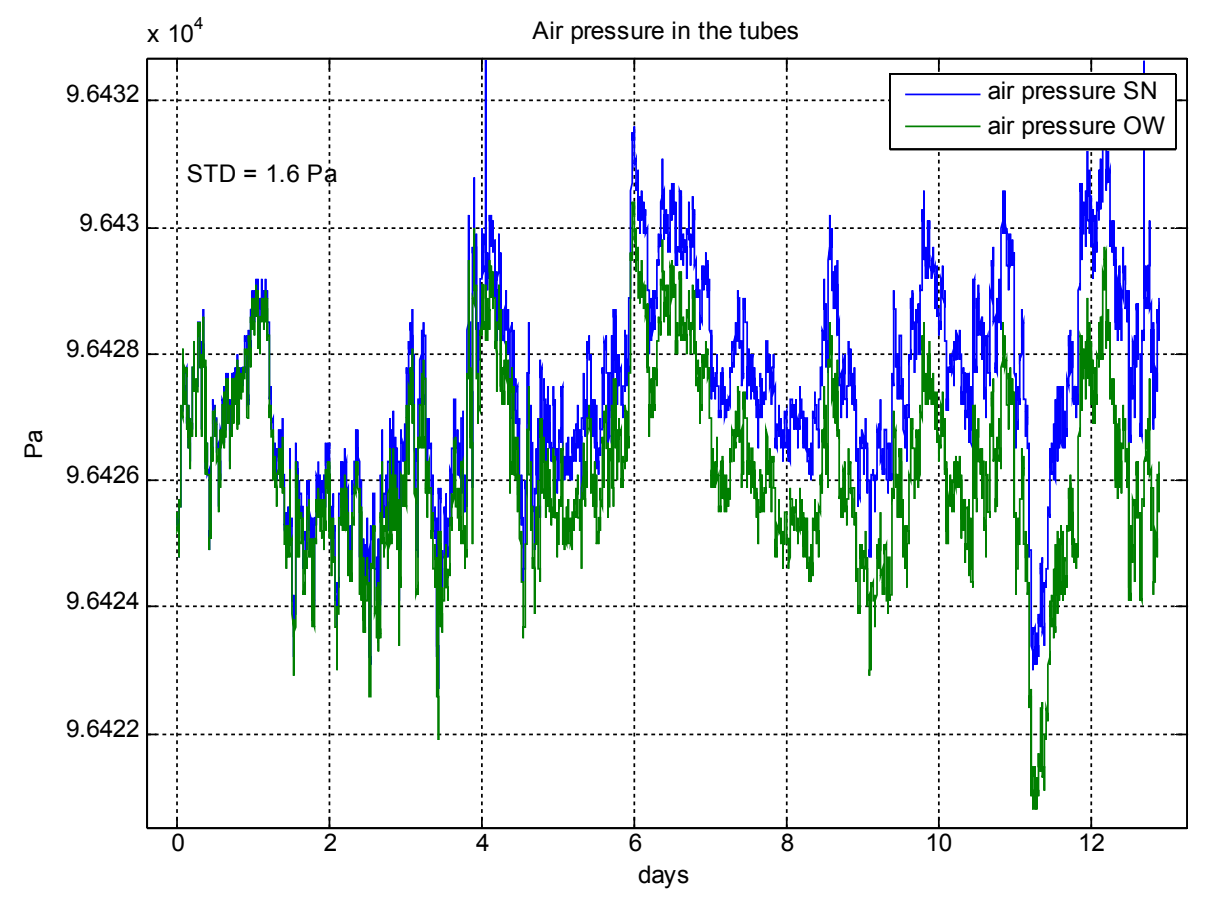

Fig. 6 Long-term air pressure stability of N-S and E-W strains

The high stable temperature and air pressure conditions of the measurements allow the direct monititoring of the earth crust deformation. Fig. 7 presents the repesentative measurung curve of the N-S laser-interferometric strainmeter.

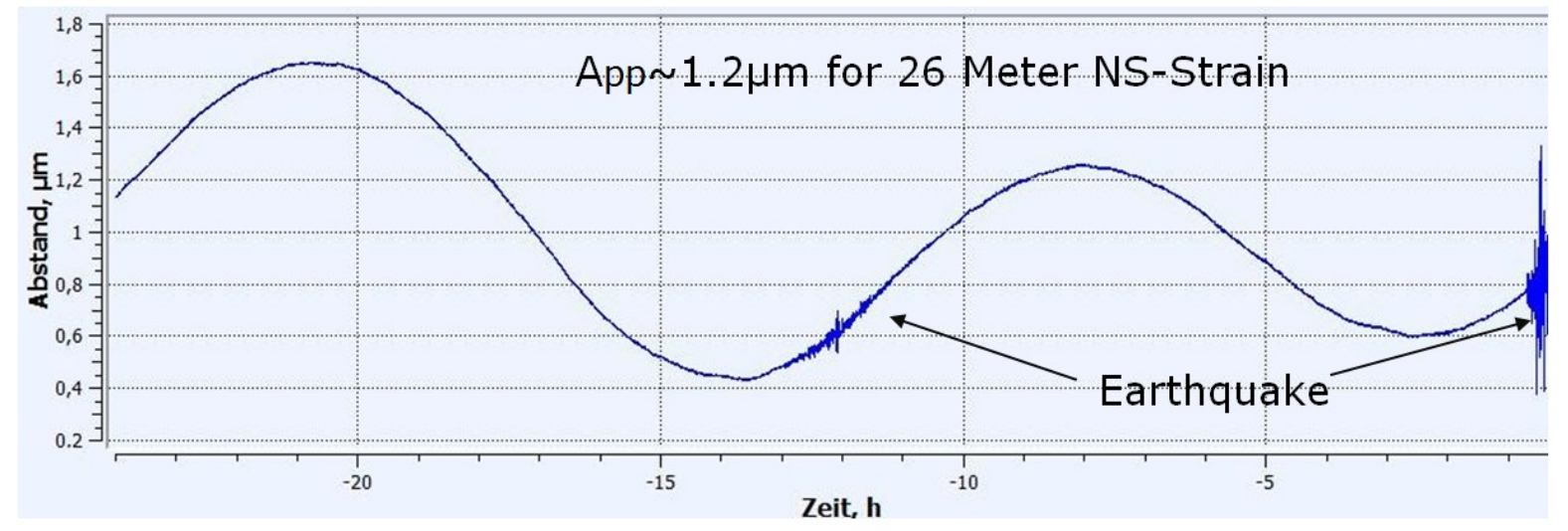

Fig. 7 Typical earth deformation curve over 24 hours

The amplitude of the curve in Fig. 7 is about $1.2 \mu \mathrm{m}$. For the stand-off distance of 26 meters it is a relative value of 4.6e-8. Such values are usually not achievable for the interferometric displacement measurements in air. The measuring curve is not noisy and is not drift affected. Even the earthquake effects, which are monitored in the observatory by different instruments can be detected in the measuring results. The data is saved every $10 \mathrm{~s}$ continuously over 24 hours. 


\section{CONCLUSION}

The paper presented an application of the fiber coupled homodyne interferometers for the tide caused earth crust deformation measurements. Three laser-interferometric strainmeters measure the crust deformation continuously over 24 hours. The interferometers for this application were designed for long-range application under the high humidity conditions. The achieved high stable condition of the measurements specially in respect to the air pressure and advanced instrumentation for measurement of the environmental parameters provided the background for successful installation of the system.

\section{REFERENCES}

[1] P.Schindler, T. Jahr, G. Jentzsch, N. Kukowski, "High Precision Deformation Monitoring at the Geodynamic Observatory Moxa/ Thuringia, Germany”, International Association of Geodesy Symposia, Volume 139, 141-147 (2014)

[2] W. Schott, W. Pöschel, S. Ecke, G. Jäger, R. Grünwald, H.-J. Büchner, E. Manske, H. Wurzbacher, „Präzision mit Laserlicht“, Laser+Photonik, Volume 1 (2003)

[3] T. Jahr, G. Jentzsch, C. Kroner "The Geodynamic Observatory Moxa/Germany: instrumentation and purposes.” J Geod Soc Jpn 47(1), 34-39 (2001)

[4] H. Ishii "Environmental effects on strain observation, their applications for geophysical study and necessity of deep borehole observation for noiselessly high quality.” Bull d’Inf Marées Terr 137, 10907-10908 (2002)

[5] H. Ishii, T. Yamauchi, S. Matsumoto, Y. Hirata, S. Nakao "Development of multicomponent borehole instrument for earthquake prediction study, some observed example of precursory and coseismic phenomena relating to earthquake swarms and application of the instrument for rock mechanics.” In: H. Ogasawara, T. Yanagidani, M. Ando(eds) Seismogenic process monitoring. Balkema, Rotterdam, 365-377 (2002)

[6] H. Ishii, T. Yamauchi, F. Kusumoto "Development of high sensitivity borehole strainmeters and application for rock mechanics and earthquake prediction study.” In:Sugawara K, Obara Y (eds) Rock stress. Proceedings of the international symposium on rock stress. Balkema, Rotterdam, 253-258 (1997)

[7] G. Jentzsch, T. Jahr, H. Ishii News from the Geodynamic Observatory Moxa: the 4component borehole strainmeter. Bull d’Inf Marées Terr 141:11245-11252 (2006)

[8] A. Gebauer, H. Steffen, C. Kroner, T. Jahr "Finite element modelling of atmosphere loading effects on strain, tilt and displacement at multi-sensor stations." Geophys J Int 181(3), 1593-1612 (2010)

[9] P.E. Ciddor "Refractive index of air: new equations for the visible and near infrared." Appl Opt 35(9), 1566-1573 (1996)

[10] P.E. Ciddor "Refractive index of air: 3. The roles of $\mathrm{CO} 2, \mathrm{H} 2 \mathrm{O}$, and refractive virials." Appl Opt 41(12), 2292-2298 (2002)

[11] B. Edlén The refractive index of air. Metrologia 2(2), 71-80 (1996)

\section{CONTACTS}

\author{
Dr.-Ing. D.Dontsov \\ Dr.-Ing. W. Schott \\ Dr.-Ing. W. Poeschel \\ Dr.-Ing. T. Jahr
}

dontsov@sios.de

schott@sios.de

poeschel@sios.de

thomas.jahr@uni-jena.de 